\title{
Discussion
}

\section{Live discussion: Are neurons just too laissez-faire about repair?}

\author{
Live discussion held 14 July 2003 on the Alzheimer Research Forum. Discussion led by Thierry Nouspikel and \\ moderated by Rachael Neve. \\ Participants: Thierry Nouspikel (Stanford University), Rachael Neve (McLean Hospital), Donna McPhie (McLean \\ Hospital), Karl Herrup (Case Western Reserve University), Randall D. York (Case Western Reserve University), \\ June Kinoshita (Alzheimer Research Forum), Greg Brewer (Southern Illinois University), Junming Wang \\ (University of Southern California), JunQing Victoria Qian (University of Southern California).
}

\begin{abstract}
Rachael Neve: I am Rachael Neve and I will be moderating this discussion. I would like to start off by summarizing Thierry Nouspikel's hypothesis, and by asking a couple of questions. My understanding, Thierry, is that you have found that NT2 cells tend to downregulate their global repair mechanisms. When you discovered that neurons are entering the cell cycle and dying in several neurodegenerative diseases, including $\mathrm{AD}$, you hypothesized that their entry into the cell cycle was causing them to die specifically due to DNA lesions that they had accumulated. Is there a precedent for this sort of model? Are there known cases in which cells of any type that have accumulated DNA lesions have died specifically because they have tried to enter the cell cycle?
\end{abstract}

Thierry Nouspikel: Let me put it this way: Introducing lesions into the DNA of dividing cells is a good way to trigger apoptosis.

Rachael Neve: What is the evidence for that?

Karl Herrup: The ATM mutant comes to mind. Behavior, but no cell loss. The XRCC4 and LigIV knockouts (recombination repair) are embryonic lethals. Lots of nerve cell death.

\footnotetext{
${ }^{1}$ Note: The transcript has been edited for clarity and accuracy.
}

Thierry Nouspikel: As far as neurons are concerned, one of our hypotheses is that re-entering the cell cycle will cause transcription of genes that were not transcribed before and are supposedly crippled with lesions. It is known that RNA PolII encountering a lot of DNA lesions is a good trigger for apoptosis.

Victoria Qian: Did any animal models with any sort of DNA repair defects see cross-correlation with neural dysfunction?

Thierry Nouspikel: Victoria, I am assuming transcription-coupled repair (TCR) is critical to maintain neuronal function. Patients with a specific deficit in TCR (Cockayne syndrome) generally die young due to neurological problems.

Karl Herrup: Then why do the XRCC4 mutants lead to such massive cell death?

Rachael Neve: We have shown that expression of FAD mutants of $\mathrm{A} \beta \mathrm{PP}$ in primary neuronal cultures causes DNA synthesis and consequent apoptosis. The primary cortical cultures from E17 embryos likely have not had time to accumulate DNA lesions. What are your thoughts about that?

Karl Herrup: I would propose that the accumulated DNA damage might play a role in explaining why AD does not start until later ages. A second hit maybe 
Rachael Neve: But Karl, you have shown that neurons can exist in the tetraploid state in AD brains for years before killing the cells. How does that compare with Thierry's hypothesis?

Karl Herrup: Good question, Rachael. I think that there is a major difference between young neurons and old neurons. The critical period of target dependence seems a breakpoint for a nerve cell.

Victoria Qian: In adult neurons, as long as survival is concerned, is transcription-coupled DNA repair more reasonable if it is ever needed?

Thierry Nouspikel: Accumulated DNA damage can block the cell cycle through dedicated genome surveillance mechanisms. The question is, how long the cell will remain in this "suspended" state before it gives up and commits suicide.

Victoria Qian: Could you further explain about target dependence?

Karl Herrup: Victoria, if a neuron does not receive trophic support from its target during development, it dies. This is believed to be a numerical matching function. We have shown that at least in some cases, this involves the deprived neurons re-entering a cell cycle.

Rachael Neve: I am still wondering why, in our cultures, we can express FAD A $\beta$ PPs, or overexpress $\mathrm{A} \beta \mathrm{PP}-\mathrm{BP} 1$, a cell cycle protein, and readily see DNA synthesis and consequent apoptosis. We have shown that if we prevent DNA synthesis, we do not prevent the apoptosis, but if we prevent the $G$ to $S$ transition, we do prevent it. That is Donna McPhie's work.

Karl Herrup: Thierry, where in the cycle does the arrest occur? And how?

Thierry Nouspikel: Karl, there may be several checkpoints. One mechanism is through the ATM/ATM Rad3-related (ATR) pathway.

Karl Herrup: Okay, but why is the neuropathology of the ATM $(-/-)$ mouse so minor? Does ATR kick in? Does anyone know how big a role ATR plays in the CNS?

Thierry Nouspikel: I do not know. It would not be the first time that mouse and man behaved differently.
Karl Herrup: I surely agree there.

Rachael Neve: Thierry, I noticed in your interview that you said you had seen downregulation of global repair mechanisms in human fetal neurons as well as in NT2 cells. How long did you maintain the human fetal neurons before seeing this downregulation?

Thierry Nouspikel: Twenty-nine weeks. Given the age of the donor, that would correspond to 42-weekold neurons. The downregulation appeared somewhat earlier, though (16 weeks, if I recall correctly).

Junming Wang: What are the check points that drive cell division activity to apoptosis?

Rachael Neve: Junming, we have shown that if you block the G1 to $\mathrm{S}$ transition, you can block neuronal apoptosis in our model.

Karl Herrup: Junming, to Rachael's comments I would add that I think my young vs. old concept applies. In the young, there may be specific checkpointrelated apoptosis pathways. In the old, I think it is more of a slow atrophy ending in an apoptotic crisis.

Randall D. York: To Rachael and Karl, it is also possible that attempts to replicate in the presence of DNA damage may signal death checkpoints in the majority of cells, but a subset escape these checkpoints and are able to progress to the tetraploid state and undergo G2 arrest, similar to what is seen in Drosophila-replication mutants. In this case, the tetraploid neurons that are surviving for prolonged periods would represent the minority.

Rachael Neve: So Karl, do you think that explains why we so readily get DNA synthesis and apoptosis in our model expressing FAD A $\beta$ PPs in embryonic neurons?

Karl Herrup: Rachael, I think it is a big contributing factor. Plus, what age of cortex are you looking at?

Rachael Neve: Karl, we use E17 cortices and do our experiments on day five in vitro.

Randall D. York: Rachael, how is the G1 to S transition blocked in this case?

Rachael Neve: Donna, what did we use? Mimosine and what else? 
Donna McPhie: Desferoxamine.

Junming Wang: Karl, for the stem cells, a lot of new cells go into apoptosis if they do not differentiate to a certain destination. Does the cell density play a role there, also?

Karl Herrup: Junming, do you think that is a DNA damage problem or a problem of apoptotic pathways?

Junming Wang: Karl, I think there may somehow be a link between cell cycle proteins and apoptosis.

Victoria Qian: Is that likely due to DNA repair mechanism or otherwise?

Rachael Neve: Thierry, is there a way to assay whether DNA from aged human brains, in fact, has accumulated global lesions relative to DNA from younger human brains?

Karl Herrup: Good question, Rachael. I have wondered about that myself. How do you tease out neurons from glia (and other things)?

Rachael Neve: Maybe you could do a microdissection from a part of the brain that is rich in neurons, like maybe from the hippocampal CA layer?

Thierry Nouspikel: There are ways. We just need to know what lesions we should look at. There are so many, repaired by various repair systems. I was using UV-induced lesions and benzopyrene, for reason of convenience (good test lesions for the nucleotide excision repair (NER) pathway). But I am aware that these may not be the best physiological lesions, at least in the brain.

Rachael Neve: I was wondering if it would be useful to cross, say, an FAD A $\beta$ PP + FAD PS transgenic with Stratagene's Big Blue mouse, and see if more mutations occur than if you crossed the Big Blue with a control mouse.

Karl Herrup: Rachael, while you are crossing, what about putting in a DNA repair glitch such as making the mice ligase IV heterozygotes?

Rachael Neve: Oh, I like that.

Karl Herrup: I would bet that Peter McKinnon would be willing to part with some animals.
Thierry Nouspikel: Karl, why not put a glitch in the NER pathway, too, just for the fun of it?

Rachael Neve: You know, it really would be a fun experiment to do. Our transgenic mouse facility is a bit overcrowded at the moment, so I imagine that there would not be a lot of rejoicing among the animal care staff, but it would be very interesting.

Victoria Qian: What are the insults used in these DNA damage models?

Thierry Nouspikel: Oxidative lesions may be more relevant for neurons, but most are repaired by another pathway (BER), and I do not know whether it is repressed in neurons. There are a few oxidative lesions repaired by NER, though (cyclopurines).

Randall D. York: Thierry, how difficult would it be to determine whether the upregulation in DNA repair enzymes and activity reported with acute oxidative stress and/or ischemia are associated with transcribed genes or global repair that may accompany attempts to replicate in neurons that have re-entered a cell cycle?

Thierry Nouspikel: Randall, I am not sure I understand your question. Are we not talking about two different models here? There are several mice deficient in one or the other NER enzyme.

Randall D. York: Perhaps, but there appears a common attempt at cell cycle re-entry in both models.

Greg Brewer: We can get two-year-old rat neurons to divide many times. Does that mean they do it with mistakes or maybe fix them first?

Rachael Neve: That is interesting, Greg. Maybe because they continue to divide, they maintain their DNA in good condition.

Karl Herrup: Greg, do you know whether your neurons might be GABAergic interneurons? We find that they seem to get around all of the restrictions we have been talking about. Those neurons might even be where some of the adult neurospheres are coming from.

Rachael Neve: Good point, Karl, and that brings up the issue of why we see regional specificity in AD neurodegeneration. 
Thierry Nouspikel: Greg, can you get them to resume dividing after they go quiescent? Or do you have to keep them growing continuously?

Victoria Qian: Greg, how did you get your old neurons to divide, if it is not a secret.

Junming Wang: Greg, I have also noticed that at a certain density, a lot of them enter apoptosis.

Greg Brewer: Karl, I do not know if they are GABAergic. Do you think they keep dividing throughout life, so that is why they can still do it?

Victoria Qian: Greg, are you using some kind of stem cell growth conditions?

Greg Brewer: Victoria, they divide readily at low density in neurobasal/B27 + FGF2 [1].

Karl Herrup: Greg, I think they retain the potential. The other thing I am not sure about is whether there may be a true "stem" cell somewhere (in response to Victoria's query).

Greg Brewer: Karl, the percentages seem too high to be stem cells: 50 percent neurofilament + BrdU positive after just five days in culture.

Karl Herrup: Greg, point taken.

Junming Wang: Are there some checkpoints that can change the direction of a cell from dividing to apoptosis pathway?

Rachael Neve: Junming, I think that is the $\$ 64,000$ question.

Thierry Nouspikel: There was a hypothesis that it is a matter of time [2]. First, the cell cycle is stopped pending damage to be repaired. If this does not occur within a certain time frame (?), then apoptosis is triggered.

Rachael Neve: Thierry, at what point is the cell cycle paused?

Thierry Nouspikel: G1, I think.

Rachael Neve: That might explain why, if we block G1 to $\mathrm{S}$, we can block apoptosis following DNA synthesis in neurons.
Thierry Nouspikel: At least it would make sense to allow time for repair before replication occurs. Although stops in $\mathrm{G} 2$ could permit repair by recombination-like events.

Greg Brewer: We have unpublished data that the neuron division restores the cytochrome oxidase levels of old neurons to those of young ones. So maybe a lot of repair is happening, not just DNA. We intend to measure mtDNA mutation levels.

Rachael Neve: Greg, that is fascinating! It will be interesting to see the results of your assays of mtDNA mutation levels.

Karl Herrup: If we set aside the problems of chromosome mechanics, would we be wise or foolish to try to get the neurons to finish the job and get through G2 and M. The upside of this is that we would have two cells instead of one. The first one was doing fine without repair. Would it hurt to have two?

Thierry Nouspikel: Probably not...assuming that replication went smoothly. How many mutations would be introduced by trying to replicate through DNA lesions?

Rachael Neve: Karl, did you have any ideas about how to get the neurons through $\mathrm{G} 2$ and $\mathrm{M}$ without them dying?

Karl Herrup: Thierry, good point. Rachael, no.

Randall D. York: Are you able to estimate the degree of damage in neuronal cells? It also seems unlikely that conventional replication could proceed without signaling checkpoints in the absence of a novel, error-prone replication mechanism.

Thierry Nouspikel: Randall, an idea is that signaling checkpoints were disabled in nondividing neurons. They may be slow to restart.

Randall D. York: I like that idea; is there any evidence for this?

Thierry Nouspikel: Randall, that is a question for the cell cycle gurus. Are some critical cell cycle-related proteins downregulated in neurons? I am sure somebody must have looked. 
Rachael Neve: Thierry, how much DNA do you need to assess DNA damage in older human brains vs. younger? Can one do it with microdissections?

Thierry Nouspikel: Rachael, for global genome, about one microgram. For gene-specific repair, $50 \mathrm{mi}-$ crograms per time point.

Rachael Neve: So you do not need that much DNA. It seems that there are neuron-rich regions of the brain one could microdissect to do the experiment. If I find a way to get the tissue and isolate the DNA, will you do the assay?

Thierry Nouspikel: Sure. But be aware that we can only look for a few specific lesions: UV-induced and some chemicals.

Karl Herrup: What about specific amplification processes? Could we envision maybe using cre-lox to create neuron-specific methods?

Rachael Neve: Thierry, we see a lot of upregulations of cell cycle proteins in AD; I am not sure if anyone has seen downregulation of any of them. Does anyone know?

Thierry Nouspikel: Not in AD. In normal, terminally differentiated neurons.

Karl Herrup: Rachael, as far as I know, everything is up. Cyclins, CDKs, CKIs, and they are everywhere.

Rachael Neve: Thierry, are you planning to continue this work of looking at DNA lesions and mechanisms by which they are produced in neurons?

Thierry Nouspikel: Yes, but for reasons of convenience I have switched to a different system (macrophages). Once I have dissected the mechanism in these cells, I will go back and look if it is the same in neurons.

Karl Herrup: Thierry, do not stay in the periphery too long. We need your talents in the CNS.

Thierry Nouspikel: The reason I went to macrophages is that I can grow billions of precursor cells, then differentiate over 90 percent of them to macrophages. This allows me to do some hardcore biochemistry. I cannot do that with neurons.
Rachael Neve: Thierry, we do some pretty hardcore biochemistry with our neuronal cultures. I do not know that we get billions, but we certainly get hundreds of millions.

Thierry Nouspikel: I was thinking of purifying an activity missing in terminally differentiated cells"to microsequence the protein. You need a lot of cell extract for that.

Rachael Neve: True. How are you assaying for that activity, by the way, Thierry?

Thierry Nouspikel: Cis-platinum cross-links in an invitro assay. Tenfold differences between macrophages and replicating precursors.

Randall D. York: Can you tell us anything about the specialized polymerases/enzymes to bypass DNA damage before replicative enzymes take over ( $\mathrm{Pol} n$; hREV$1)$, and their role in neuronal cells.

Thierry Nouspikel: There are several DNA polymerases that can sail through DNA lesions, with or without introducing mutations in the process. There is also a repair pathway known as "daughter-strand gap repair" that can fill the gaps left by a DNA polymerase puzzled by a DNA lesion in its template.

Rachael Neve: Thierry, are those specific pathways downregulated in neurons?

Thierry Nouspikel: I do not know.

Randall D. York: It may be interesting to consider these in differentiated neurons as well. In the event that checkpoint pathways are not downregulated, there must be mechanisms in place to avoid apoptotic signals, particularly in the tetraploid AD neurons.

Karl Herrup: I wonder if there is something to be gained from looking at primary neurons vs. neuroblastomas. To be fair, it would have to be a PNS/neuroblastoma comparison. But clearly, cell division kills the primary PNS neuron but leaves the neuroblastoma untouched.

Victoria Qian: Mitochondria are so heterogeneous and capable of rapidly reproducing to replace themselves; is mtDNA repair crucial for neuron survival, or is $\mathrm{mtD}$ NA repair limited because mitochondria can rapidly replicate? 
Thierry Nouspikel: It is certainly important. Several people work on the topic. Susanne Ledoux jumps to mind, but there are others.

Greg Brewer: Glenn Wilson is another one working on mtDNA repair. I suspect neurons will keep getting more plastic, the more we study them.

June Kinoshita: As the editor of the Alzforum, I want to thank you all for participating in today's chat. We are at the end of our allotted time. I was wondering if you would all like to submit some closing thoughts regarding the scientific opportunities offered by the convergence of Thierry's work and AD research. What next?

Rachael Neve: I like the idea of crossing transgenic mice using Big Blue, as Karl and I discussed earlier.

Victoria Qian: So, neurons are working hard on DNA repair even in adult, is that a consensus?

Karl Herrup: I agree with Rachael that there are some interesting crosses to do to compromise cells in different ways and then stress their neurons with cell cycle stressors. To keep Thierry engaged, we should compare these with macrophages (and other cells) from the same animals. It could be very good.

Rachael Neve: I want to thank Thierry for presenting a most provocative hypothesis.

\section{References}

[1] G.J. Brewer, Regeneration and proliferation of embryonic and adult rat hippocampal neurons in culture, Exp Neurol 159 (1999), 237-247.

[2] M.S. Meyn, Ataxia-telangiectasia and cellular responses to DNA damage, Cancer Res 55 (1995), 5991-6001. 